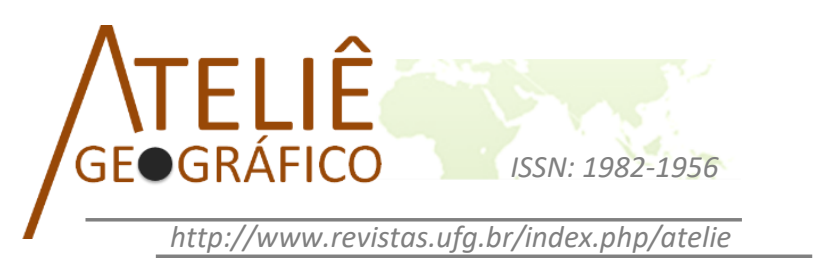

\title{
Dispersão metropolitana e novas formas urbano-regionais: uma proposta para o reconhecimento e a delimitação da cidade-região de Belém
}

\author{
Metropolitan dispersal and new urban-regional forms: a \\ proposal for recognition and limits of the city-region of \\ Belém
}

\begin{abstract}
Dispersión metropolitana y nuevas formas urbanoregionales: una propuesta para el conocimiento y la delimitación de la ciudad-región de Belém
\end{abstract}

\author{
Willame de Oliveira Ribeiro \\ Universidade do Estado do Pará \\ willame.geo@gmail.com
}

\begin{abstract}
Resumo
Belém compõe um dos principais e mais complexos espaços urbanos brasileiros. Caracterizado como metropolitano, sua simples delimitação já é um grande desafio, pois seu espraiamento resultou num significativo processo de dispersão das características metropolitanas. É nesse contexto que se insere a questão central desse trabalho: qual a abrangência territorial do fenômeno metropolitano constituído por Belém e a forma assumida por ele? Os procedimentos metodológicos utilizados envolvem aprofundamento teórico com relação aos principais conceitos envolvidos na problemática, levantamentos documentais, trabalhos exploratórios de campo e o uso dos dados de deslocamento temporário de pessoas por motivo de trabalho e por motivo de estudo como indicadores das interações espaciais. Os resultados obtidos apontam que Belém estruturou um espaço metropolitano mais conciso, envolvendo outros municípios, e também um outro espaço mais amplo, no entorno, com interações fortes com o núcleo metropolitano e que inclui não apenas centros locais, mas também outros centros de expressão regional, constituindo, desse modo, uma cidade-região.
\end{abstract}

Palavras-chave: Dispersão metropolitana, interações espaciais, cidade-região, Belém.

\footnotetext{
Abstract

Bethlehem makes up one of the main and most complex Brazilian urban spaces. Characterized as metropolitan, its simple definition is already a major challenge, because its spreading resulted in a significant process of dispersion of the
} 
metropolitan characteristics. It is in this context that the central issue of this work is inserted: what is the territorial scope of the metropolitan phenomenon constituted by Bethlehem and the form assumed by him? The methodological procedures used affect theoretical studies regarding the main concepts involved in the problem: documentary surveys, exploratory work in the field and the use of temporary displacement data of people either for work purposes or for reasons of studying as spatial interactions indicators. The results suggest that Bethlehem structured a more concise metropolitan area, involving other municipalities, and another broader space also, the environment, with strong interactions with the metropolitan core, which includes not only local centers, but also other regional expression centers, constituting thereby a city-region.

Keywords: metropolitan dispersion, spatial interactions, city-region, Bethlehem.

\begin{abstract}
Resumen
La ciudad de Belém constituye uno de los principales y más complejos espacios urbanos brasileños. Caracterizado como metropolitano, su simple delimitación ya constituye un grande reto, pues su difusión dio como resultado una dispersión significativa de las características metropolitanas. Es en este contexto que se inserta la cuestión central de este trabajo: ¿cuál es la amplitud territorial del fenómeno metropolitano constituido por la ciudad de Belém y la forma? Los procedimientos metodológicos utilizados envuelven una profundización teórica con relación a los principales conceptos involucrados en la problemática, tales como encuestas documentales, trabajos expiatorios de campo y el uso de datos acerca del traslado temporal de personas por motivo de trabajo o por motivo de estudio como como indicadores de las interacciones espaciales. Los resultados obtenidos indican que Belém estructuró un espacio metropolitano más conciso involucrando otros municipios, y también otro espacio más amplio, en el entorno, con interacciones fuertes tales como el núcleo metropolitano que incluye no sólo centros locales, sino también otros centros de expresión regional, constituyendo de este modo una ciudad-región.
\end{abstract}

Palabras Clave: Dispersión metropolitana, interacciones espaciales, ciudad-región, Belém.

\title{
Introdução
}

Certos espaços urbanos, aqueles reunidos sob a nomenclatura de metrópole, atingem na atualidade um nível de complexidade cada vez maior, que se expressa, entre outros fatores, na densidade e espraiamento dos sistemas de objetos e na intensidade e multidirecionalidade dos fluxos. E essa situação cria uma série de novos desafios para a compreensão e para a gestão desses espaços, que perpassam, inclusive, por procedimentos, em princípio simples, mas de fato muito complicados, como a sua própria delimitação.

Belém, capital do Estado do Pará e um dos espaços urbanos de caráter metropolitano da Amazônia brasileira, se insere nesse contexto, enquanto espaço marcado por grande complexidade. Apesar da influência regional dessa metrópole já ter sido bem mais ampla, hoje ela ainda abrange os territórios dos Estado do Pará e Amapá, uma pequena parte do Maranhão e do Tocantins (IBGE, 2013). 
Essa expressão regional de Belém se traduz também no espraiamento de seu espaço urbano, que, por meio de um processo de dispersão das características metropolitanas acabou constituindo um espaço cada vez mais extenso e integrado. A instituição da Região Metropolitana de Belém tenta dar conta dessa realidade, porém, como em praticamente todo o Brasil, a sua delimitação é muito carente de fundamentos e envolta de uma diversidade de questões, que muitas vezes não privilegiam o reconhecimento da real ocorrência do fenômeno metropolitano.

É nesse contexto que se insere a indagação central desse artigo: qual a abrangência territorial do fenômeno metropolitano constituído por Belém e a forma assumida por ele? A resposta a essa questão é aqui perseguida por meio da utilização da concepção de interações espaciais, neste caso, para identificar o espaço com intensidade de interações espaciais condizente com o qualificativo metropolitano.

Os procedimentos metodológicos utilizados para o alcance da reposta ao problema apresentado estão assim dispostos: 1) Aprofundamento teórico com relação aos principais conceitos envolvidos na problemática, como os de metrópole, metropolização, interações espaciais e cidade-região; 2) Levantamento documental a respeito da constituição metropolitana de Belém e da sua formalização enquanto região metropolitana, bem como das revisões feitas em relações aos seus limites; 3) Trabalhos exploratórios de campo, voltados principalmente para análise da disposição dos sistemas de objetos na Região Metropolitana de Belém - RMB; 4) Utilização dos dados de deslocamento temporário de pessoas por motivo de trabalho e por motivo de estudo (IBGE, 2010) como indicadores das interações espaciais dos diversos municípios paraenses com Belém, visando o reconhecimento daqueles com maior intensidade de interações com a metrópole.

Além desse tópico introdutório, constam no artigo quatro seções. A primeira se volta à análise das concepções de metrópole e metropolização e à interpretação do processo de metropolização de Belém. A segunda apresenta a concepção de interações espaciais e sua potencialidade para a análise do fenômeno metropolitano e logo em seguida já discute os indicadores propostos para a interpretação da realidade de Belém. A terceira parte se dedica à concepção de cidade-região e à verificação de sua compatibilidade com o caso concreto de Belém. E na quarta seção, que também conclui o trabalho, apresenta-se a proposição dos contornos da cidade-região de Belém com base nos indicadores discutidos.

\section{A metropolização de Belém}

Di Méo (2008) considera que o termo metropolização faz referência a processos, que caracterizam "[...] tanto as formas quanto as funções e as dinâmicas dos maiores agrupamentos humanos de nosso tempo" (p. 03), mas ressalta que o mesmo não pode ser confundido com o processo de urbanização nem com a globalização: 
[...] a metropolização que não significa urbanização stricto sensu, e nem se confunde totalmente com a globalização [...], se observa a partir de um nível mínimo de concentrações humanas mais ou menos difusas. Trata-se de um mínimo pouco preciso, o de aglomerações de algumas centenas de milhares de habitantes (se avizinhando a um milhão?) dispostos em torno de um ou de vários centros urbanos... Até constituir conjuntos territoriais agrupando de uma a duas, ou até três dezenas de milhões de indivíduos, dentre os mais expressivos entre eles.

O autor reconhece no âmbito dos espaços qualificados como metropolitanos uma grande diversidade de realidades, abrangendo desde metrópoles regionais ou nacionais, cuja importância está basicamente restrita aos territórios nacionais, a metrópoles mundiais, que desempenham papéis de grande destaque, especialmente na gestão de grandes empresas.

Segundo Di Méo (2008), as metrópoles desempenham uma série de papéis fundamentais relativos à economia, à cultura, à política e à ideologia e "[...] concernem, no mais alto nível, o governo dos homens, de suas atividades, de seus valores. Elas constroem uma rede mundial, um tipo de tecido de centralidades combinando lógicas hierárquica e resilientes" (p. 02). Destaca a centralidade exercida pela metrópole, ou seja, sua condição de "cabeça e matriz de rede", associada a uma forte capacidade de atração e organização.

Metrópoles, como explica Souza (2003), são espaços urbanos complexos nucleados por uma cidade grande, dotados de uma área de influência pelo menos regional. Constituídas como aglomerações de cidades, não necessariamente apresentam conurbações ${ }^{1}$, pois núcleos urbanos descontínuos, do ponto de vista do espaço físico, podem fazer parte das metrópoles. Indispensável à configuração da metrópole, na visão de Souza (2003, p. 33):

[...] é que todos os espaços urbanos se achem fortemente 'costurados', especialmente com a ajuda da 'linha' mais importante, sob esse aspecto, que são os deslocamentos diários de trabalhadores, grande parte dos quais trabalha no núcleo metropolitano e reside nas cidades vizinhas a este.

Desse modo, o espaço metropolitano é, por excelência, um espaço relacional (HARVEY, 1980, 2012), pois a metrópole se constitui enquanto tal na relação permanente e reiterada com outros centros urbanos, formando uma área de influência. Além disso, o espaço metropolitano, na maior parte dos casos, somente é alcançado quando se consideram os fluxos, já que a descontinuidade é cada vez mais comum, como será enfatizado mais adiante. O conceito de metrópole apresentado por Ribeiro, Silva e

\footnotetext{
${ }^{1}$ Entendido como em Villaça (1997), enquanto um processo de fusão de áreas urbanas, mais ou menos contíguas e pertencentes a municípios diferentes.
} 
Rodrigues (2011, p. 179) está em consonância com essas considerações. Para eles a metrópole refere-se

[...] a aglomerados urbanos que apresentam as dimensões de polarização e concentração no território brasileiro nas escalas nacional, regional e local. A metrópole é identificada então como um espaço urbano com características metropolitanas que, internamente, também apresenta uma hierarquização, já que é um aglomerado com concentração de poder econômico, social, cultural que não é semelhante para todos os espaços, no caso, municípios nele inseridos. Entretanto, tais espaços apresentam níveis de integração à dinâmica do aglomerado correspondente, maior ou menor conforme o município.

Assim, os autores destacam elementos como a polarização (ou a centralidade), a aglomeração de municípios, os níveis variados de integração dos municípios e a concentração de poder econômico, social e cultural como fatores caracterizadores da metrópole. Mais adiante em seu trabalho, sintetizam que o termo metrópole é por eles usado para se referir a "[...] espaços urbanos complexos e grandes [...] conjuntos de unidades político-administrativas (municípios) diversas, com diferentes tamanhos e níveis de integração entre essas unidades, que conjuntamente apresentam caráter metropolitano" (RIBEIRO, SILVA e RODRIGUES, 2011, p. 193).

No Brasil, o reconhecimento oficial desse caráter metropolitano tem sido comumente envolto de muitas polêmicas e contradições. As primeiras regiões metropolitanas brasileiras passaram a existir formalmente nos anos 1970, mais precisamente a partir de 1973, por força da Lei Complementar 14, subordinada à Constituição de 1967. A partir da Constituição de 1988, a responsabilidade de criação e organização das regiões metropolitanas deixou de pertencer à esfera federal e passou para a estadual, como definia seu $\S 3^{\circ}$ do Artigo 25 (RIBEIRO, SILVA, RODRIGUES, 2011).

A partir de então, como demonstram diversos autores, entre eles, Moura e Firkowski (2001), a criação de regiões metropolitanas passou a ser marcada por forte imprecisão conceitual e a obedecer a interesses os mais diversos, o que ocasionou, em muitos casos, o distanciamento entre a institucionalidade da região metropolitana e a realidade do espaço metropolitano. Nesse contexto, Ribeiro, Silva e Rodrigues (2011) constataram em 2010 a existência no Brasil de 35 Regiões Metropolitanas (RMs) e 3 Regiões Integradas de Desenvolvimento Econômico (RIDEs) definidas por legislação federal ou estadual, como demonstra o Quadro 01. 
Quadro 01: Regiões Metropolitanas e RIDEs segundo as grandes regiões - 2010.

\begin{tabular}{|c|c|c|c|c|}
\hline NORTE & NORDESTE & SUDESTE & SUL & $\begin{array}{l}\text { CENTRO- } \\
\text { OESTE }\end{array}$ \\
\hline $\begin{array}{c}\text { Belém (PA) } \\
\text { Macapá (AP) } \\
\text { Manaus (AM) }\end{array}$ & $\begin{array}{c}\text { Aracaju (SE) } \\
\text { Agreste (AL) } \\
\text { Cariri (CE) } \\
\text { Fortaleza (CE) } \\
\text { Grande São Luís (MA) } \\
\text { João Pessoa (PB) } \\
\text { Maceió (AL) } \\
\text { Natal (RN) } \\
\text { RIDE Petrolina/Juazeiro } \\
\text { RIDE Teresina/Timon } \\
\text { Salvador (BA) } \\
\text { Sudoeste Maranhense } \\
\text { (MA) }\end{array}$ & $\begin{array}{c}\text { Baixada Santista } \\
\text { (SP) } \\
\text { Belo Horizonte } \\
\text { (MG) } \\
\text { Campinas (SP) } \\
\text { Grande Vitória } \\
\text { (ES) } \\
\text { Rio de Janeiro } \\
\text { (RJ) } \\
\text { São Paulo (SP) } \\
\text { Vale do Aço } \\
\text { (MG) }\end{array}$ & $\begin{array}{c}\text { Carbonífera } \\
\text { (SC) } \\
\text { Chapecó (SC) } \\
\text { Curitiba (PR) } \\
\text { Florianópolis } \\
\text { (SC) } \\
\text { Foz do Itajaí } \\
\text { (SC) } \\
\text { Lages (SC) } \\
\text { Londrina (PR) } \\
\text { Maringá (PR) } \\
\text { Norte/Nordeste } \\
\text { Catarinense } \\
\text { (SC) } \\
\text { Porto Alegre } \\
\text { (RS) } \\
\text { Tubarão (SC) } \\
\text { Vale do Itajaí } \\
\text { (SC) }\end{array}$ & $\begin{array}{c}\text { Goiânia (GO) } \\
\text { RIDE Distrito } \\
\text { Federal } \\
\text { Vale do Rio } \\
\text { Cuiabá (MT) }\end{array}$ \\
\hline
\end{tabular}

Fonte: Ribeiro, Silva e Rodrigues (2011).

Objetivando superar as distorções que marcam a definição formal das regiões metropolitanas e reconhecer os espaços que realmente manifestam características metropolitanas, o Observatório das Metrópoles desenvolveu o estudo "Hierarquização e Identificação dos Espaços Urbanos" (RIBEIRO, 2009), que ao considerar o termo Região Metropolitana esvaziado de conteúdo e precisão, como resultado das incoerências das legislações que institucionalizam as regiões metropolitanas no país, fez opção por trabalhar com o termo aglomeração metropolitana ou área metropolitana, que corresponderia à

[...] mancha de ocupação contínua ou descontínua diretamente polarizada por uma metrópole, onde se realizam as maiores intensidades de fluxos e as maiores densidades de população e atividades, envolvendo municípios com alto grau de integração ou englobando parcialmente ou inteiramente apenas a área do município central (RIBEIRO, 2009, pp. 3 e 4).

O resultado da aplicação dessa concepção foi o reconhecimento de 15 aglomerados metropolitanos ou áreas metropolitanas no Brasil, como exposto no Quadro 02, que reconhece São Paulo como a área metropolitana de maior nível hierárquico, ou seja, a de maior destaque com relação à concentração de atividades econômicas e população e que exerce maior centralidade. O quadro também trata do nível de integração entre os municípios que compõem cada aglomerado e do nível de 
concentração das atividades e da população no município polo. E, por fím, expõe a caracterização da condição social vivenciada em cada área metropolitana.

Quadro 02: Categoria na hierarquia, nível de integração, grau de concentração e condição social das áreas metropolitanas brasileiras

\begin{tabular}{|c|c|c|c|c|}
\hline $\begin{array}{c}\text { Área } \\
\text { metropolitana }\end{array}$ & $\begin{array}{c}\text { Categoria na } \\
\text { Hierarquia }\end{array}$ & Integração & Concentração & Condição social \\
\hline São Paulo & 1 & Muito alta & Menos concentrada & Muito boa \\
\hline Rio de Janeiro & 2 & Muito alta & Concentrada & Boa \\
\hline Belo Horizonte & 3 & Média & Menos concentrada & Média alta \\
\hline Porto Alegre & 3 & Média & Menos concentrada & Boa \\
\hline Brasília & 3 & Muito alta & Muito concentrada & Média baixa \\
\hline Curitiba & 3 & Média & Concentrada & Boa \\
\hline Salvador & 3 & baixa & Concentrada & Média alta \\
\hline Recife & 3 & Média & Menos concentrada & Ruim \\
\hline Fortaleza & 3 & Média & Concentrada & Ruim \\
\hline Campinas & 4 & Média & Menos concentrada & Muito boa \\
\hline Manaus & 4 & - & - & Média baixa \\
\hline Vitória & 4 & Alta & Menos concentrada & Média alta \\
\hline Goiânia & 4 & Média & Muito concentrada & Média alta \\
\hline Belém & 4 & Alta & Muito concentrada & Média baixa \\
\hline Florianópolis & 4 & Alta & Concentrada & Muito boa \\
\hline
\end{tabular}

Fonte: Ribeiro (2009).

A área metropolitana de Belém pertence à categoria 4 na hierarquia, com uma alta integração entre os municípios componentes do aglomerado, mas com muita concentração de atividades econômicas e população no município polo e com uma condição social média baixa. O trecho a seguir apresenta maiores detalhes sobre a caracterização do Observatório das Metrópoles.

A área de maior integração à dinâmica metropolitana nessa RM é composta pela própria cidade de Belém, Ananindeua, Marituba e Benevides, cabendo ressaltar que esta integração é mais forte, entre Belém e Ananindeua, onde se localiza a maior parte dos 1.991 .542 habitantes da área. A densificação na rede de transportes e a emergência de outros centros urbanos têm diminuído a importância relativa de Belém no conjunto da rede urbana nacional. Ainda assim, Belém mantém seu poder polarizador, o que se revela nos indicadores selecionados, sediando quatro empresas dentre as 500 maiores do Brasil, empregando 9.869 pessoas em atividades de ponta, apresentando total de 78 agências bancárias e movimento 
aéreo de passageiros de mais de um milhão de pessoas. Na área de metropolização mais densa localiza-se um total de 92.058 domicílios carentes e 57.840 domicílios deficientes. $\mathrm{Na}$ classificação por condição social, apenas Belém e Ananindeua estão em situação média, os demais municípios desta região metropolitana estão em situação ruim (RIBEIRO, 2009, p. 65).

Dos municípios que compunham a Região Metropolitana de Belém em 2009, data de publicação do estudo, o município de Santa Bárbara foi considerado menos integrado à dinâmica metropolitana, sendo que os demais possuíam boa integração, com destaque a Belém e Ananindeua.

O processo de metropolização de Belém tem início nos anos 1960 e se consolida nas décadas posteriores, segundo Trindade Júnior (1998), sendo basicamente marcado pela incorporação de cidades e vilas próximas e pela consequente constituição de uma malha urbana única e, ao mesmo tempo, fragmentada. Segundo o autor, esse processo de metropolização apresenta dois momentos diferentes que se traduzem em duas formas urbanas distintas: a forma urbana confinada e a forma urbana dispersa.

Como explica Trindade Júnior (1998), a forma urbana confinada é definida pela restrição da expansão urbana aos limites impostos por um conjunto de instituições públicas situado nos limites de Belém e que passou a atuar como uma barreira à expansão horizontal da cidade. Esse conjunto de instituições ficou conhecido como "cinturão institucional" e foi instalado durante a segunda guerra mundial. Essa forma urbana foi caracterizada pela ocupação das baixadas, pelo adensamento populacional e pela valorização dos terrenos de topografia mais elevada e, portanto, não sujeitos às inundações. Por sua vez, a forma urbana dispersa se constitui por meio da superação da barreira representada pelo cinturão institucional nos anos 1960 e a expansão da malha urbana para “[...] localidades até então consideradas distantes, notadamente, para a Rodovia Augusto Montenegro (eixo Belém-Icoaraci) e para a BR-316 (eixo BelémAnanindeua) [...]” (TRINDADE JÚNIOR, 1998, p. 104).

Na década de 1980, esses eixos de expansão e, por conseguinte, a forma urbana dispersa, são consolidados. Os novos espaços de assentamento, que davam concretude a forma urbana dispersa, passaram a ser o destino de uma grande massa populacional, que se deslocava da área central de Belém, especialmente das baixadas que passavam por um processo de valorização resultante de obras de infraestrutura.

Os novos espaços de assentamento eram fortemente marcados pelo conteúdo de periferia urbana e, assim, o processo de metropolização de Belém em muito se confunde com um processo de produção de espaços periféricos, que, de início, funcionavam como 'cidades dormitórios', isto é, como locais de residência de população de baixa renda, que ao trabalhar na área central de Belém necessitava realizar um movimento diário entre o local de trabalho e o de moradia.

No que se refere à dimensão legal, a Região Metropolitana de Belém - RMB foi institucionalizada, por lei estadual, em 19 de outubro de 1995. A Lei Complementar $n^{\circ}$ 027, reconhecia a RMB enquanto composta pelos municípios de Belém, Ananindeua, 
Marituba, Benevides e Santa Bárbara do Pará (DIÁRIO OFICIAL DO ESTADO DO PARÁ, 22/12/1995).

Depois disso, outros municípios foram acrescentados à RMB. Este é o caso de Santa Isabel do Pará - Lei Complementar $\mathrm{n}^{\circ}$ 072, de 20 de abril de 2010, publicada no DOE N 31.656 , de 30/04/2010) - e também de Castanhal - Lei Complementar n. 076, de 28 de dezembro de 2011- (DIÁRIO OFICIAL DO ESTADO DO PARÁ, 28/12/2011). Desse modo, na atualidade, a RMB é composta pelos municípios de Belém, Ananindeua, Marituba, Benevides, Santa Bárbara do Pará, Santa Isabel do Pará e Castanhal (Figura 01). Contudo, muitas indagações ainda restam a respeito do real conteúdo metropolitano desse recorte como um todo.

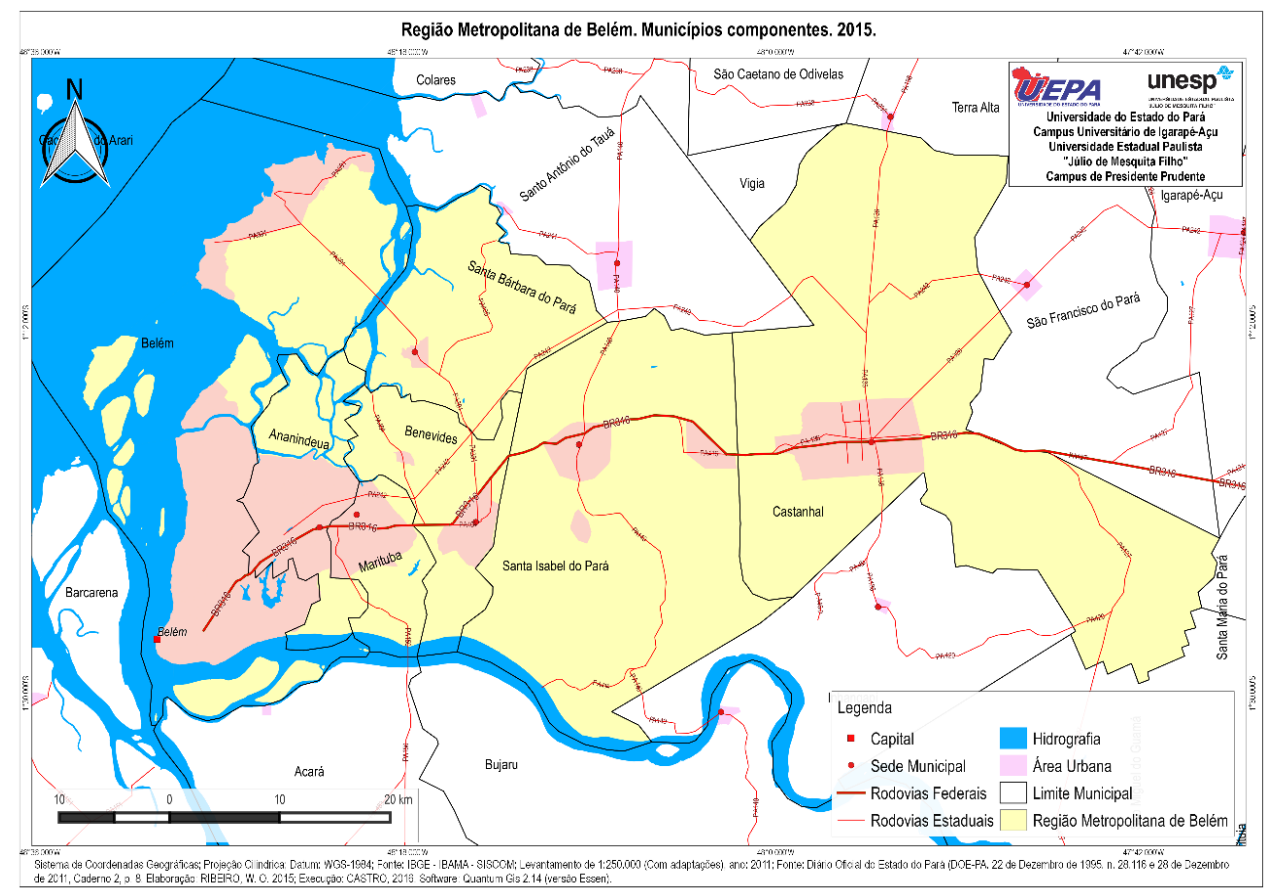

Figura 01. Mapa da Região Metropolitana de Belém. Municípios componentes. 2015.

Fonte: Diário Oficial do Estado do Pará. 22 de dezembro de 1995. n. 28.116 e 28 de dezembro de 2011, caderno 2, p. 8.

Belém, Ananindeua, Marituba e Benevides formam um conjunto com claras características metropolitanas, já a inserção de Santa Bárbara do Pará, Santa Isabel do Pará e Castanhal, são bem mais questionáveis.

Com vistas a uma melhor apreensão do fenômeno metropolitano é que se propõe a utilização das interações espaciais como uma forma de reconhecimento da inserção ou não de certos espaços em contextos metropolitanos. Interação espacial, para Ullman (1980), se constitui enquanto um conceito associado à noção de situação 
espacial, ou seja, que se volta à análise de conexões, de relacionamentos, de movimentos, da circulação entre locais, enfim, às diversas atividades e ações que interligam espaços. Com isso, o conceito seria importante instrumento para analisar processos como interdependência entre regiões, difusão e centralização.

Na mesma perspectiva, em obra mais recente, Corrêa (1997) assim define as interações espaciais:

As interações espaciais constituem um amplo e complexo conjunto de deslocamentos de pessoas, mercadorias, capital e informação sobre o espaço geográfico. Podem apresentar maior ou menor intensidade, variar segundo a frequência de ocorrência e, conforme a distância e direção, caracterizar-se por diversos propósitos e se realizar através de diversos meios e velocidades (p. 279).

Essa interpretação está diretamente associada à compreensão do espaço de um ponto de vista relacional, como na formulação de Harvey (1980, 2012). As interações espaciais entre as cidades são componentes da sua própria realidade, especialmente, daquela constituída pelo seu conjunto em uma escala regional. Entretanto, é pertinente realçar que as interações espaciais são processos e, como tais, não ocorrem desagregados da sociedade, ao contrário, são geradas pelos interesses, conflitos e práticas da sociedade a partir de seus agentes e atores. Isto posto, é possível identificar a origem das interações espaciais nas ações de sujeitos sociais concretos, como pessoas em suas práticas cotidianas, instituições e empresas.

$\mathrm{Na}$ presente análise, as interações espaciais serão consideradas a partir do deslocamento temporário de pessoas para fins de trabalho e para fins de estudo com destino a Belém. A partir da variabilidade da intensidade das interações espaciais se espera diferenciar aqueles municípios que de fato estão inseridos no espaço metropolitano de Belém daqueles que não o compõem, mesmo que oficialmente integrem a RMB.

\section{As interações espaciais a partir do deslocamento de pessoas como estratégia para reconhecer a forma metropolitana}

A fonte dos dados de deslocamento de pessoas é o censo demográfico de 2010 (IBGE, 2010). Esse deslocamento de pessoas será aqui denominado Deslocamento Populacional Temporário ${ }^{2}$, sendo compreendido como um deslocamento diário, semanal

\footnotetext{
${ }^{2}$ A opção pela utilização desse termo ao invés de migração ou movimento pendular se deve às restrições impostas por essas concepções. Conforme Carvalho e Rigotti (1998), o conceito de migração não incorpora os indivíduos que ao fazer o deslocamento para outra área não estabelecem nela residência fixa. "Refere-se, portanto, às mudanças permanentes de residência. Geralmente, os movimentos sazonais, temporários e os de populações nômades não são considerados migração" (p. 211). Por sua vez, o movimento pendular consiste num deslocamento diário, não implicando a fixação definitiva em outro lugar (MOURA; BRANCO; FIRKOWSKI, 2005).
} 
ou até mensal entre o local de residência e o local de trabalho ou de acesso a determinado serviço, na presente análise, de estudo.

Esses deslocamentos serão considerados sob duas perspectivas: o quantitativo de pessoas que se desloca e a intensidade desse deslocamento. A intensidade é mensurada a partir da divisão do número de pessoas que realizaram o deslocamento por trabalho ou por estudo pela população total do município de origem em 2010, multiplicado por 1000. Esse procedimento gerou o Índice de Intensidade do Deslocamento Temporário por Trabalho - I.I.D.T.T. e o Índice de Intensidade do Deslocamento Temporário por Estudo - I.I.D.T.E. Com isso se obtém a relativização da intensidade do fluxo de acordo com o contingente populacional do município de origem.

A intensidade dos deslocamentos temporários por trabalho e por estudo se constitui num importante critério para o reconhecimento dos espaços que expressam a intensidade e a complexidade de interações condizentes com o qualificativo metropolitano.

A Tabela 1 e a Figura 2 apresentam os principais municípios de origem dos deslocamentos temporários por trabalho que se destinavam a Belém em 2010. Visando evidenciar os fluxos mais significativos, foram considerados apenas os que possuíam número igual ou maior que 200 indivíduos realizadores do deslocamento.

$\mathrm{Na}$ Tabela 1, nota-se que Ananindeua, Marituba e Benevides apresentam números muitos mais significativos que os demais municípios com relação aos deslocamentos para Belém, tanto no que diz respeito à quantidade absoluta de indivíduos que se deslocam quanto no que se refere à intensidade do fluxo. Ananindeua com 65.621 indivíduos que se deslocam e 139 de Índice de Intensidade do Deslocamento Temporário por Trabalho - I.I.D.T.T., Marituba com 10.879 indivíduos e 101 de I.I.D.T.T. e Benevides com 3.827 pessoas que se deslocam e 74 de I.I.D.T.T.

Como evidencia a Figura 2, esses são justamente os municípios mais próximos a Belém, sendo que Ananindeua e Marituba estão conurbados com a capital paraense e Benevides está em vias de também se tornar. O fluxo que parte deles é representado por linhas mais escuras e espessas, representando a maior intensidade das interações espaciais.

A acentuada intensidade dos deslocamentos por motivo de trabalho destinados à Belém e com origem em Ananindeua, Marituba e Benevides ratifica a forte articulação que eles possuem com Belém e a resultante constituição de uma estrutura urbana metropolitana. Com relação aos municípios que estão na sequência de intensidade dos deslocamentos temporários por trabalho, eles estão numa posição intermediária, apresentando considerável integração com Belém e o espaço metropolitano, porém não com a intensidade suficiente a sua inclusão nesse espaço. 
Tabela 1: Deslocamentos temporários de pessoas por motivo de trabalho com destino ao Município de Belém/PA em 2010

\begin{tabular}{|c|c|c|c|c|}
\hline & $\begin{array}{l}\text { MUNICÍPIO DE } \\
\text { ORIGEM }^{3}\end{array}$ & $\begin{array}{l}\text { QUANTIDADE DE } \\
\text { PESSOAS }\end{array}$ & $\begin{array}{c}\text { POPULAÇÃO DO } \\
\text { MUNICÍPIO DE ORIGEM }\end{array}$ & I.I.D.T.T. ${ }^{4}$ \\
\hline 1 & Ananindeua & 65621 & 471.980 & 139 \\
\hline 2 & Marituba & 10879 & 108.246 & 101 \\
\hline 3 & Benevides & 3827 & 51.651 & 74 \\
\hline 4 & $\begin{array}{l}\text { Santa Bárbara do } \\
\text { Pará }\end{array}$ & 761 & 17.141 & 44 \\
\hline 5 & $\begin{array}{l}\text { Santo Antônio do } \\
\text { Tauá }\end{array}$ & 596 & 26.674 & 22 \\
\hline 6 & Santa Isabel do Pará & 1193 & 59.466 & 20 \\
\hline 7 & Salinópolis & 319 & 37.421 & 9 \\
\hline 8 & Vigia & 396 & 47.889 & 8 \\
\hline 9 & Castanhal & 1319 & 173.149 & 8 \\
\hline $\begin{array}{l}\mathbf{1} \\
\mathbf{0}\end{array}$ & Igarapé-Açu & 218 & 35.887 & 6 \\
\hline $\begin{array}{l}1 \\
1\end{array}$ & Barcarena & 606 & 99.859 & 6 \\
\hline $\begin{array}{l}1 \\
2\end{array}$ & Abaetetuba & 758 & 141.100 & 5 \\
\hline $\begin{array}{l}\mathbf{1} \\
\mathbf{3}\end{array}$ & Igarapé-Miri & 305 & 58.077 & 5 \\
\hline $\begin{array}{l}\mathbf{1} \\
\mathbf{4}\end{array}$ & $\begin{array}{l}\text { São Miguel do } \\
\text { Guamá }\end{array}$ & 253 & 51.567 & 5 \\
\hline $\mathbf{1}$ & Capanema & 225 & 63.639 & 4 \\
\hline $\begin{array}{l}1 \\
6\end{array}$ & Bragança & 281 & 113.227 & 2 \\
\hline
\end{tabular}

Estes municípios ${ }^{5}$ são: Santa Bárbara do Pará, com 761 pessoas que se deslocam e 44 de I.I.D.T.T.; Santo Antônio do Tauá com 596 indivíduos e 22 de

\footnotetext{
${ }^{3}$ Foram considerados apenas os municípios do Estado do Pará com 200 ou mais indivíduos que realizaram deslocamentos temporários por motivo de trabalho com destino a Belém, uma vez que se buscam as interações mais significativas.

${ }^{4}$ Índice de Intensidade do Deslocamento Temporário por Trabalho - alcançado a partir da divisão do número de pessoas que realizaram o deslocamento por trabalho pela população total do município de origem em 2010 , multiplicado por 1000 .

Fonte: IBGE (2010)

${ }^{5}$ Salinópolis, que ocupa a sétima posição na intensidade de emissão de pessoas para trabalho em Belém (Tabela 1 e Figura 2), não foi abordada no texto por desenvolver uma interação muito particular com Belém, já
} 
I.I.D.T.T.; Santa Isabel do Pará, com 1193 pessoas e 20 de I.I.D.T.T.; Vigia, com 396 pessoas e 8 de I.I.D.T.T.; e Castanhal, com 1319 indivíduos e também 8 de I.I.D.T.T. De forma simplificada, eles se estabelecem por meio de centros urbanos com relações relevantes com a metrópole, mas não como parte integrante dela.

Esse segundo grupo de municípios, que tem seu fluxo de pessoas por motivo de trabalho para Belém representado por linhas na cor vermelha (Figura 2), apresenta maiores distâncias em relação à Belém, caso se compare com os 3 municípios do primeiro grupo, e corresponde a um entorno metropolitano com significativas interações com a metrópole de Belém.
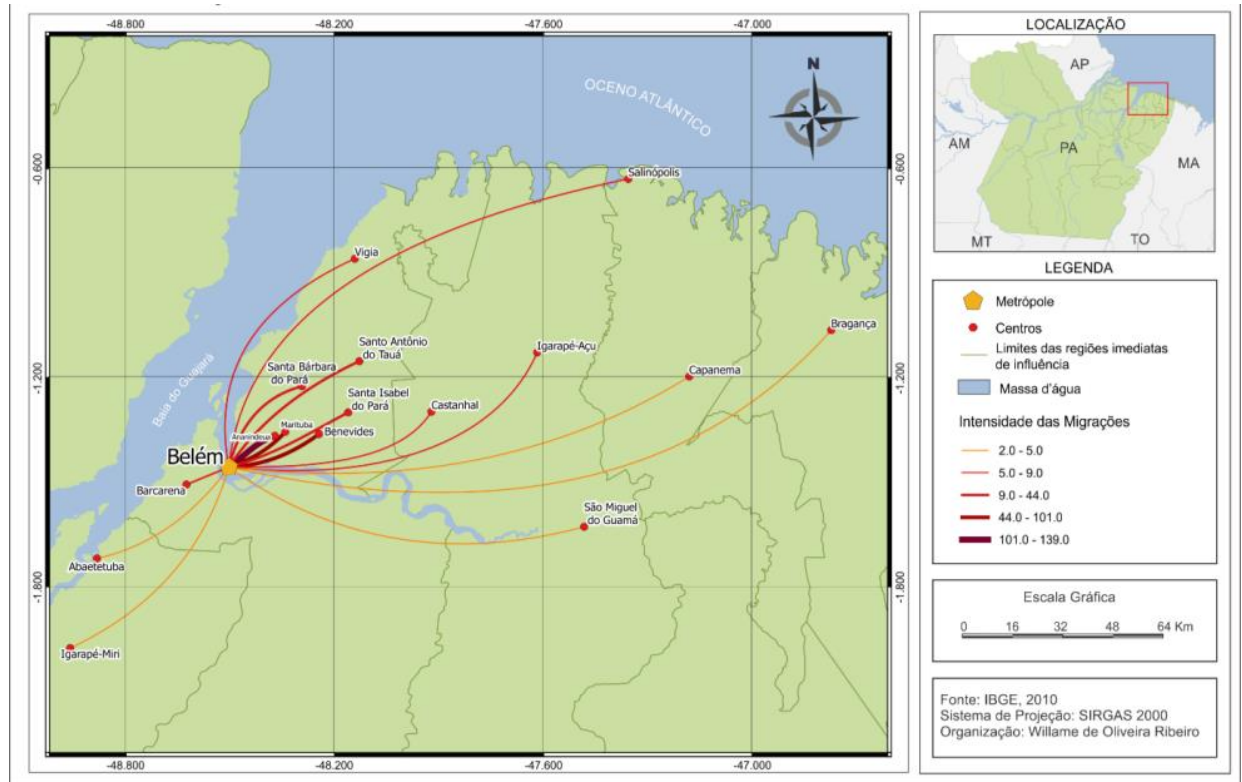

Figura 02. Mapa da intensidade dos deslocamentos temporários de pessoas por motivo de trabalho com destino à Belém. 2010.

Fonte: Elaboração própria com base em dados de IBGE (2010).

Os municípios que ocupam as posições de 10 a 16 (Tabela 1 e Figura 2) formam um terceiro conjunto, com deslocamentos temporários por trabalho para Belém em intensidade bem mais reduzida, o que os afasta da realidade metropolitana.

A análise dos dados de deslocamento temporário por motivo de estudo para Belém segue os mesmos parâmetros dos deslocamentos por trabalho. E, por sua vez, a Tabela 2 e a Figura 3 seguem a mesma tendência da discussão anterior, ao retratar uma

que sua condição de balneário regional resulta numa forte expressão do processo de metropolização do espaço, na forma considerada por Lencioni (2013), contudo, marcada pela sazonalidade. Dessa forma, as interações espaciais entre Salinópolis e Belém são bem menos contínuas e estáveis no tempo do que aquelas desenvolvidas pelos demais municípios. 
intensidade fortemente realçada de Ananindeua, Benevides e Marituba enquanto origens dos deslocamentos temporários por motivo de estudo para Belém.

Ananindeua com 22.745 pessoas que se deslocam e 48 de Índice de Intensidade do Deslocamento Temporário por Estudo - I.I.D.T.E.; Benevides com 1.156 pessoas e 22 de I.I.D.T.E.; e Marituba com 2.235 e 21 de I.I.D.T.E. A maior intensidade dos deslocamentos por estudo com origem nesses municípios e destino em Belém, representada na Figura 3 pela coloração mais escura e espessa da linha de fluxo, atesta a condição de espaço metropolitano para Belém e para os três municípios próximos.

Tabela 02. Deslocamentos temporários de pessoas por motivo de estudo com destino ao Município de Belém/PA em 2010.

\begin{tabular}{|c|c|c|c|c|}
\hline & $\begin{array}{l}\text { MUNICÍPIO DE } \\
\text { ORIGEM }^{6}\end{array}$ & $\begin{array}{l}\text { QUANTIDADE DE } \\
\text { PESSOAS }\end{array}$ & $\begin{array}{c}\text { POPULAÇÃO DO } \\
\text { MUNICÍPIO DE ORIGEM }\end{array}$ & I.I.D.T.E. ${ }^{7}$ \\
\hline 1 & Ananindeua & 22745 & 471.980 & 48 \\
\hline 2 & Benevides & 1156 & 51.651 & 22 \\
\hline 3 & Marituba & 2235 & 108.246 & 21 \\
\hline 4 & Barcarena & 1125 & 99.859 & 11 \\
\hline 5 & $\begin{array}{l}\text { Santo Antônio do } \\
\text { Tauá }\end{array}$ & 248 & 26.674 & 9 \\
\hline 6 & $\begin{array}{c}\text { Santa Isabel do } \\
\text { Pará }\end{array}$ & 470 & 59.466 & 8 \\
\hline 7 & Castanhal & 1130 & 173.149 & 7 \\
\hline 8 & Vigia & 274 & 47.889 & 6 \\
\hline 9 & Abaetetuba & 486 & 141.100 & 3 \\
\hline 10 & Capanema & 210 & 63.639 & 3 \\
\hline 11 & Paragominas & 206 & 97.819 & 2 \\
\hline 12 & Tucuruí & 201 & 97.128 & 2 \\
\hline 13 & Ananindeua & 22745 & 471.980 & 48 \\
\hline 14 & Cametá & 215 & 120.896 & 2 \\
\hline 15 & Marabá & 234 & 233.669 & 1 \\
\hline
\end{tabular}

Fonte: IBGE (2010).

\footnotetext{
${ }^{6}$ Foram considerados apenas os municípios do Estado do Pará com 200 ou mais indivíduos que realizaram deslocamentos temporários por motivo de estudo com destino a Belém, uma vez que se buscam as interações mais significativas.

7 Índice de Intensidade do Deslocamento Temporário por Estudo - alcançado a partir da divisão do número de pessoas que realizaram o deslocamento por estudo pela população total do município de origem em 2010, multiplicado por 1000 .
} 
Barcarena, Santo Antônio do Tauá, Santa Isabel do Pará, Castanhal e Vigia compõem um segundo conjunto de municípios, com intensidades dos deslocamentos temporários por estudo bem inferior ao primeiro conjunto. Nesse segundo grupo, os números absolutos variam de 274 a 1125 pessoas que se deslocam a Belém por motivo de estudo, equivalendo a Índices de Intensidade de Deslocamentos Temporários por Estudo de 6 a 11. Com fluxos identificados por linhas de cor vermelha na Figura 3, esses municípios formam um entorno metropolitano. Isto porque, a característica dos fluxos indica que se tratam de espaços não metropolitanos, não obstante são atingidos pela dispersão metropolitana, o que faz com que desenvolvam interações estreitas com o espaço metropolitano, principalmente com Belém.

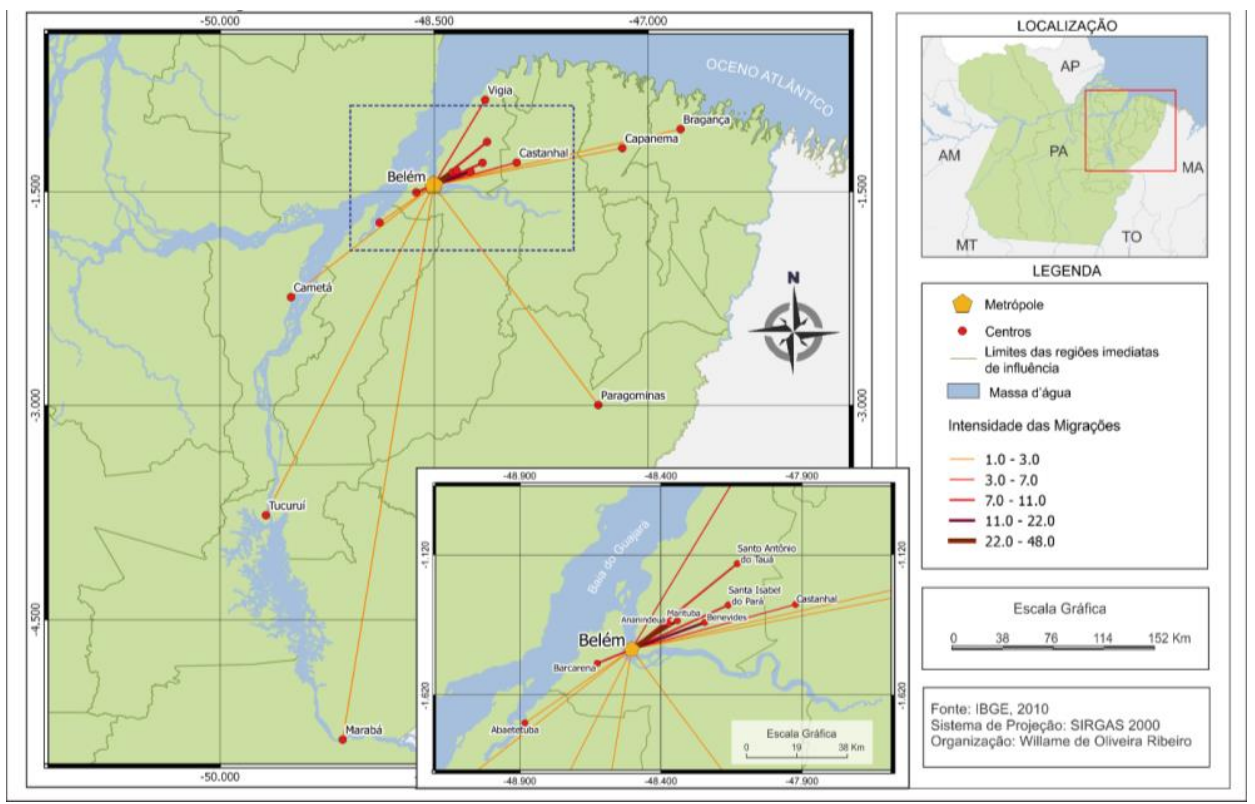

Figura 03. Mapa da intensidade dos deslocamentos temporários de pessoas por motivo de estudo com destino à Belém. 2010.

Fonte: Elaboração própria com base em dados de IBGE (2010).

Por fim, Abaetetuba, Capanema, Paragominas, Tucuruí, Bragança, Cametá e Marabá, os municípios com intensidades de deslocamentos temporários por motivo de estudo para Belém mais reduzidas, cuja representação na Figura 3 se dá pelas linhas na cor laranja, apesar de serem fluxos relevantes, do contrário não estariam presentes na Tabela 2 e na Figura 3, possuem um distanciamento relacional bem maior de Belém que o registrado pelos municípios dos dois primeiros conjuntos.

Por conta disso, esse último conjunto é considerado aqui como não pertencente ao que a seguir será definido como cidade-região de Belém, pois entre esses municípios 
e a metrópole se percebe um abrandamento das interações espaciais, quando se compara com os dois primeiros grupos analisados. De fato, o número ainda significativo de deslocamentos por motivo de estudo desses municípios com Belém é decorrência da posição de destaque que esses ocupam em outras porções do território paraense. Ou seja, não se deve a sua inserção no quadro metropolitano, mas às funções de intermediação desempenhadas por esses municípios em relação às suas regiões de influência e a metrópole Belém.

\section{A concepção de cidade-região}

$\mathrm{Na}$ análise dos dados apresentados no item anterior é possível constatar que, considerando o espaço de um ponto de vista relacional, a metrópole de Belém possui com Ananindeua, Marituba e Benevides uma intensidade das interações espaciais muito maior que a constatada na relação de Belém com outros municípios, o que justifica a caracterização dos referidos municípios como componentes do espaço metropolitano de Belém. Entretanto, não é possível desconsiderar as importantes interações de Belém com outros municípios, mesmo que não no mesmo nível dos anteriormente citados. Desse modo, torna-se necessário pensar em uma forma urbana que vá além do espaço metropolitano mais restrito, abarcando a relação da metrópole com sua região, que se mostra expressiva a partir dos dados estudados.

Uma das marcas do mundo contemporâneo tem sido a crescente imbricação entre a concepção de espaço urbano e de região. São cada vez mais frequentes espaços urbanos, principalmente metropolitanos, que atingem uma amplitude regional. Neste contexto, proliferaram conceitos que fazem referência a essa condição, porém valorizando particularidades dos fenômenos observados em cada realidade. Moura (2009) destaca, nesse sentido, os conceitos de megalópole, cidade difusa, metápole, cidade dispersa, cidade-região global e megarregião.

Mas apesar da relevância desses vários conceitos, considera-se neste trabalho que a concepção de cidade-região é a que demonstra maior coerência com a realidade vivenciada em Belém e região. A concepção de cidade-região está presente na obra de vários autores brasileiros nas últimas décadas e, entre esses, Magalhães (2008) evidencia grande proximidade com o entendimento deste trabalho sobre o conceito em questão nesse momento. Para ele a cidade-região consiste na forma contemporânea do processo de metropolização, apresentando descontinuidades e continuidades com relação aos processos anteriores. Sendo mais que uma metrópole estendida, ela se concretiza quando "[...] o processo de urbanização dos entornos metropolitanos começa a se intensificar e a ter suas lógicas integradas ao tecido metropolitano, através de um aumento também dos fluxos do núcleo metropolitano para o seu entorno e vice-versa" (p. 11).

Desse modo, as descontinuidades no espaço físico e a configuração de um espaço relacional são marcas fundamentais dessa forma urbana. Magalhães define a cidade-região como "[...] a área metropolitana mais concisa somada de seu entorno imediato, incluindo uma série de centralidades de pequeno e médio porte no alcance dos processos de metropolização" (2008, p. 9). 
O que o autor nomeia de "área metropolitana concisa" é aqui denominado espaço metropolitano, ou seja, um espaço cujos sistemas de objetos e os sistemas de ações (SANTOS, 2009) são densos, multifacetados e articulados de forma diferenciada dos outros espaços. Já o entorno imediato não é considerado parte do espaço metropolitano, mas sim articulado com ele. Desse modo, a cidade-região envolve, tanto o espaço metropolitano quanto o entorno diretamente articulado a ele, constituindo assim uma forma urbano-regional de caráter relacional, onde a contiguidade física nem sempre está presente.

Delgado (2003), ao também tratar da concepção de cidade-região, considera esta como constituída por três subespaços distintos: a área urbana conurbada, a coroa regional e a periferia regional. O primeiro equivaleria ao espaço metropolitano em si, ou seja, aquele que apresenta claramente as características em termos de densidade, diversidade e complexidade econômica, política, cultural etc. que marcam a metrópole. O segundo, a coroa regional, seria o espaço periurbano próximo, não conurbado, onde ocorrem os processos de difusão econômica, social e urbana. E o terceiro, a periferia regional, que apesar de integrar a cidade-região, não manifesta em seu espaço os processos de difusão.

A coroa regional reúne os principais centros urbanos do entorno metropolitano, que desenvolvem papel fundamental da organização do território. Para Delgado (2003, p. 44):

\begin{abstract}
Em suma, a coroa regional constitui o primeiro contorno não conurbado de uma cidade-região (assim sua urbanização é fragmentária) é o âmbito ad hoc para a descentralização intrarregional (assim é muito dinâmica) e é lugar "dobradiça" [...] onde se concentra uma mudança de escala entre o regional e o metropolitano (assim é necessário analisar ambas as escalas). Por todos esses motivos, na coroa regional reside o principal potencial de reestruturação da cidade-região a que pertence. ${ }^{8}$
\end{abstract}

Considera-se aqui bastante pertinentes as contribuições de Delgado, especialmente no que se refere ao reconhecimento das diferenciações internas à cidaderegião e a unidade garantida a partir dos fluxos, constituindo, assim, um espaço eminentemente relacional. Lencioni (2006) corrobora com essa compreensão ao conceber a cidade-região como produto do processo de metropolização do espaço que, em algumas metrópoles,

[...] tanto renova suas áreas urbanas como estende sua área territorial por meio da incorporação de cidades, formando um novo

\footnotetext{
${ }^{8}$ No original: "En suma, la corona regional constituye el primer contorno no conurbado de una ciudad-región (por lo que su urbanización es fragmentaria), es el ámbito ad hoc para la descentralización intrarregional (por lo que es muy dinámica) y es lugar "gozne" o "bisagra" en donde se concentra un cambio de escala entre lo regional y lo metropolitano (por eso es necesario analizar ambas as escalas a la vez). Por todos estos motivos, en la corona regional reside el principal potencial de reestructuración de la ciudad-región a la que pertenece.
} 
aglomerado metropolitano que se constitui num verdadeiro epicentro de fluxos de capitais, onde a densidade das redes territoriais encontra maior densidade e complexidade. Ao mesmo tempo, há alterações nas centralidades urbanas e redefinições das funções do núcleo metropolitano [...].

Por outro lado, há uma grande transformação nas cidades pequenas e médias do entorno metropolitano que passam a apresentar hábitos culturais e representações de valores urbanos que até então eram exclusivos ao viver nas metrópoles (LENCIONI, 2006, p. 72).

Para a autora, a grande dificuldade está em se delimitar essa cidade-região, pois, uma vez sendo, antes de mais nada, um espaço de fluxos, o limite territorial também é fortemente fluido. Contudo, o deslocamento de pessoas e mercadorias, entre outras possibilidades, oferece as pistas para o reconhecimento dos contornos e limites da cidade-região, que tem nas descontinuidades e nas múltiplas centralidades algumas de suas principais marcas.

A concepção de cidade-região envolve realidade urbanas bastante diversas, desde aquelas que possuem papel eminentemente regional (como é o caso de Belém) àquelas que possuem conexões profundas e que desempenham papéis fundamentais no âmbito da economia global, as cidades-regiões globais de Scott; Agnew; Soja; Storper (2001), que funcionariam como nós espaciais e atores políticos no mundo globalizado.

Com base no referencial e nos dados discutidos até agora, já é possível fazer algumas reflexões a respeito da forma urbana constituída pela metrópole de Belém e sua região. Levando em consideração que Belém estruturou um espaço metropolitano mais conciso, envolvendo outros municípios, e também um outro espaço mais amplo, no entorno, com interações fortes com o núcleo metropolitano e que inclui não apenas centros locais, mas também outros centros de expressão regional, opta-se, aqui, pela utilização do conceito de cidade-região enquanto ferramenta teórica mais coerente para se interpretar essa realidade.

\section{Conclusão: a cidade-região de Belém}

A Figura 04 mostra a cidade-região de Belém, como resultado dos dados de interações espaciais apresentados anteriormente. Existem dois espaços distintos no interior dessa forma urbana, o espaço metropolitano e o entorno metropolitano, de acordo com as diferenças observadas em termos de densidades dos sistemas de objetos e dos sistemas de ações (SANTOS, 2009), constituindo, assim, para o espaço metropolitano, um espaço mais denso e moderno, com uma maior força do meio técnicocientífico-informacional; e para o entorno metropolitano, um espaço menos denso e com menor expressão desse novo meio geográfico e de seus conteúdos associados ao processo de globalização.

Partindo da compreensão de Haesbaert (2010) a respeito da necessidade de integrar os princípios da homogeneidade ou da coesão, que enfatiza a diferenciação 
espacial, e o princípio da integração regional ou da articulação, que privilegia as interações e as ações dos agentes e atores na geração de fluxos, enquanto fundamentais a uma nova proposição para o conceito de região, é possível atestar a configuração do espaço metropolitano envolvendo Belém, Ananindeua, Marituba e Benevides.

Belém e Ananindeua se destacam tanto na densidade de seus espaços quanto na integração entre si. Do ponto de vista populacional, por exemplo, a somatória das populações dos dois municípios, segundo IBGE (2010), totaliza 1.865.379 dos 2.025.276 habitantes de todo o espaço metropolitano em 2010. Essa situação vai encontrar correspondência na densidade de serviços e infraestrutura, enfim, nos sistemas de objetos e nos sistemas de ações.

Mas apesar desse destaque de Belém e Ananindeua, os quatro municípios compõem um todo bastante e cada vez mais integrado, inclusive, com um processo de conurbação entre os centros muito avançado, onde se verificam, com muito mais clareza, as marcas do processo de metropolização, nesse caso, de um processo de dispersão metropolitana a partir do núcleo metropolitano, o que fica evidente na presença das redes varejistas de Belém, nas franquias modernas, no número de agências bancárias etc.

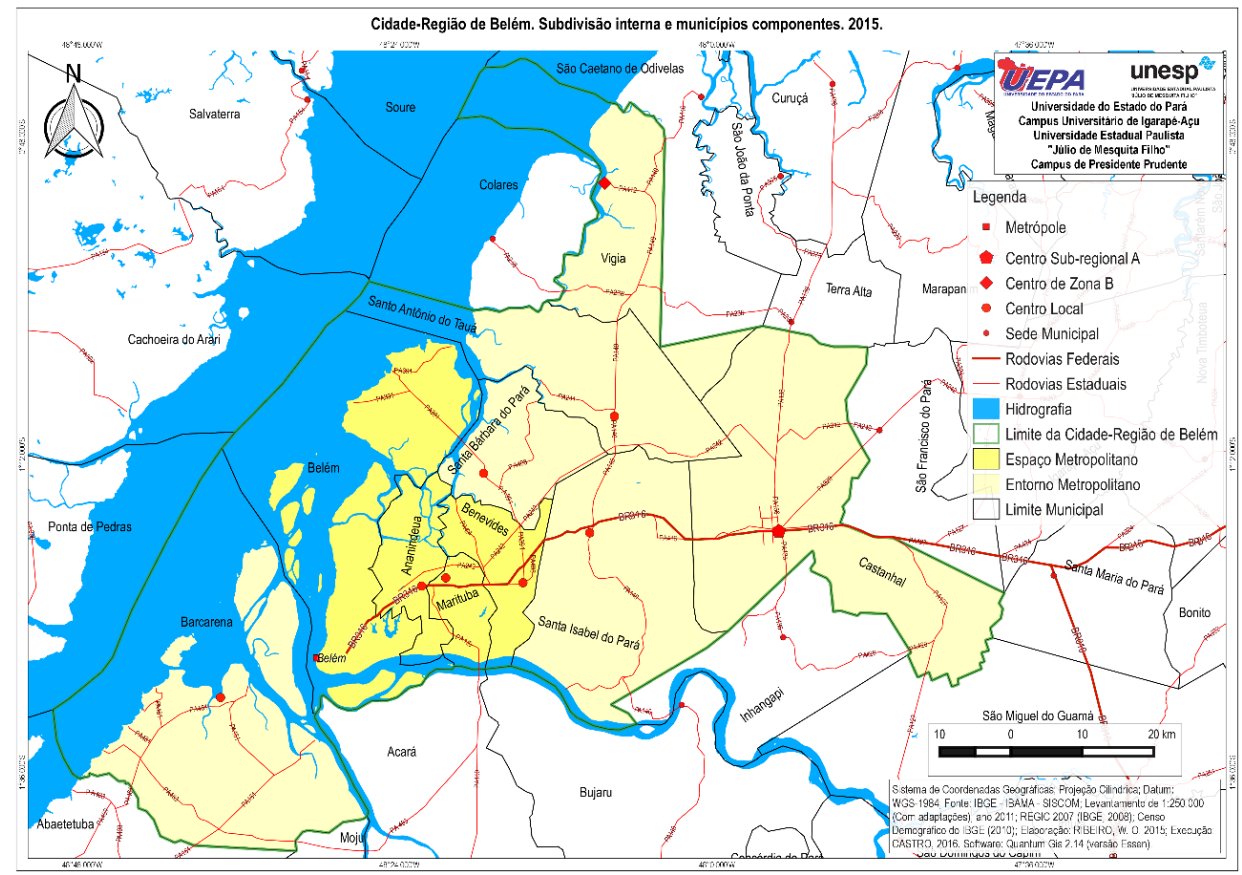

Figura 04. Mapa da Cidade-Região de Belém. Municípios componentes e localização no Estado do Pará. 2015.

Fonte: Elaboração própria a partir de IBGE (2008 e 2010). 
Esse processo de dispersão metropolitana formou uma estrutura urbana integrada entre esses centros, ou seja, as relações entre esses municípios possuem uma natureza que poderia ser denominada como intraurbana ${ }^{9}$, na qual o centro de Belém funciona como centro principal e os centros dos vários municípios desempenham papéis de subcentros do espaço metropolitano, o que inclusive resulta na tendência à formação de mais de uma centralidade no mesmo município, como no caso de Ananindeua, onde o complexo de conjuntos habitacionais Cidade Nova acabou conformando um subcentro, que, em vários setores, concentra mais serviços e comércio, que o centro principal de Ananindeua.

Desse modo, o reconhecimento dos dois subespaços componentes da cidaderegião de Belém, o espaço metropolitano e o entorno metropolitano, tem validade do ponto de vista da diferenciação de áreas, da coesão espacial ou do princípio da homogeneidade, sempre relativa, do espaço. Entretanto, esse ainda não é o principal fator diferenciador para a presente abordagem, que privilegia o caráter relacional do espaço e, portanto, as interações espaciais como expressão dessa natureza do espaço. E por esse critério, as diferenças entre esses dois subespaços reconhecidos no interior da cidade-região de Belém ficam ainda mais evidentes, como mostraram os dados dos itens anteriores, que deixam claro a imbricação muito forte de Ananindeua, Marituba e Benevides com a metrópole de Belém.

Já o entorno metropolitano (Figura 4), que inclui Barcarena, Santo Antônio do Tauá, Vigia, Santa Bárbara do Pará, Santa Isabel do Pará e Castanhal reúne cidades com uma natureza bastante diversa daquelas que compõem o espaço metropolitano. A maior parte dessas cidades estão na categoria de centros locais, de acordo com IBGE (2008), à exceção de Vigia, caracterizado como centro de zona B, por polarizar um centro local, São Caetano de Odivelas; e de Castanhal, classificado na hierarquia urbana como centro sub-regional A, polarizando 12 centros locais. Castanhal, inclusive, é fundamental ao reconhecimento da cidade-região de Belém, já que o conceito exige a existência de outros centros com expressão regional.

Essas cidades são consideradas como integrantes da cidade-região de Belém, enquanto entorno metropolitano, por possuírem com a metrópole uma articulação forte, expressa nas interações espaciais, a partir do deslocamento de pessoas e mercadorias, trabalhadas anteriormente. Do ponto de vista de uma homogeneidade relativa, essas cidades se diferenciam bastante do espaço metropolitano, possuindo uma menor densidade do espaço urbano e uma presença menor do meio técnico-científicoinformacional (SANTOS, 2009). A exceção fica por conta de Castanhal, que possui espaço urbano mais denso e moderno, mas como expressão de outro papel regional desempenhado pela cidade, o de cidade média.

\footnotetext{
9 Segundo Villaça (2001) o espaço intraurbano tem sua estruturação marcada, principalmente, pelo deslocamento de pessoas (mais do que pela circulação de mercadorias) e teria o mesmo significado que espaço urbano. Para efeitos desse trabalho o espaço urbano, ou espaço intraurbano, se refere ao espaço que compõe a cidade, enquanto um tecido urbano integrado com seus sistemas de objetos e sistemas de ações (SANTOS, 2009) característicos.
} 
As cidades do entorno metropolitano não compõem com Belém um espaço intraurbano, nos termos definidos anteriormente. Em geral, são cidades monocêntricas, isto é, que possuem um único centro relevante de comércio e serviços e que não resultam da dispersão metropolitana de Belém, enquanto um processo de dispersão de população, de serviços, de comércio etc. a partir do núcleo metropolitano, diferentemente daqueles municípios que compõem o espaço metropolitano. A dispersão metropolitana, para esses municípios, se refere a um processo mais amplo, onde tanto existe a chegada de agentes da metrópole como também se evidencia um papel relevante de agentes locais. A modernização, o crescimento e a complexificação dos seus espaços urbanos resultada das ações de agentes e atores de diversas origens.

\section{Referências}

CARVALHO, J. A. M. de; RIGOTTI, J. I. R. Análise das metodologias de mensuração das migrações. In: ENCONTRO NACIONAL SOBRE MIGRAÇÃO, 2, 1998, Anais... Curitiba, IPARDES/FNUAP, p.211-227, 1998.

CHAVEIRO, E. F.; ANJOS, A. F. dos. A periferia urbana em questão: um estudo socioespacial de sua formação. Boletim Goiano de Geografia, v. 27, n. 2. Goiânia: UFG, 2007.

CHAVEIRO, E. F. Interações espaciais. In: CASTRO, I. E. de; CORRÊA, R. L; GOMES, P. C. da C. Explorações geográficas. Rio de Janeiro: Bertrand Brasil, 1997.

DELGADO, J. La urbanización difusa, arquetipo territorial de la ciudad-región.

Sociológica, año 18, n. 51, 2003.

DIÁRIO OFICIAL DO ESTADO DO PARÁ. Belém: IOEPA. 22 DE DEZEMBRO DE 1995. n. 28.116.

DIÁRIO OFICIAL DO ESTADO DO PARÁ. Belém: IOEPA. 28 DE DEZEMBRO DE 2011, CADERNO 2, p. 8.

DI MÉO, G. Introdução ao debate sobre a metropolização. Confins [Online], n. 4, 2008.

HAESBAERT, R. Regional-Global: dilemas da região e da regionalização na geografia contemporânea. Rio de Janeiro: Bertrand Brasil, 2010.

HARVEY, D. A justiça social e a cidade. São Paulo: Hucitec, 1980.

HARVEY, D. O espaço como palavra-chave. GEOgraphia, v. 14, n. 28, 2012.

INSTITUTO BRASILEIRO DE GEOGRAFIA E ESTATÍSTICA. Regiões de Influência das Cidades 2007. Rio de Janeiro: IBGE, 2008. 
INSTITUTO BRASILEIRO DE GEOGRAFIA E ESTATÍSTICA. Censo Demográfico Brasileiro. Rio de Janeiro: IBGE, 2010.

INSTITUTO BRASILEIRO DE GEOGRAFIA E ESTATÍSTICA. Divisão Urbano Regional. Rio de Janeiro: Diretoria de Geociência/ Coordenação de Geografia, 2013.

LENCIONI, S. Da cidade e sua região à cidade-região. In: SILVA, J. B. da; LIMA, L. C; ELIAS, D. (Orgs.). Panorama da geografia brasileira I. São Paulo: Annablume, 2006.

LENCIONI, S. Metropolização do espaço: processos e dinâmicas. In: FERREIRA, Á; RUA, J; MARAFON, G. J; SILVA, A. C. P. da (Orgs.). Metropolização do espaço: gestão territorial e relações urbano-rurais. Rio de janeiro: Consequência, 2013.

MAGALHÃES, F. N. C. Da metrópole à cidade-região: na direção de um novo arranjo espacial metropolitano? Revista Brasileira de Estudos Urbanos e Regionais, v. 10, n. 2 I novembro 2008.

MOURA, R; FIRKOWSKI, O. L. Metrópoles e regiões metropolitanas: o que isso tem em comum? In: IX Encontro Nacional da ANPUR, 2001, Rio de Janeiro. Anais... Rio de Janeiro: ANPUR, 2001, v.1, p. 105- 114.

MOURA, R; CASTELLO BRANCO, M. L. G; FIRKOWSKI, O. L. Movimento pendular e perspectivas de pesquisas em aglomerados urbanos. São Paulo em perspectiva, v. 19, n. 4, p. 121-133, out./dez. 2005.

MOURA, R. Arranjos urbano-regionais no Brasil: uma análise com foco em Curitiba: Programa de Pós-Graduação em Geografia, Curso de Doutorado em Ciências da Terra, Universidade Federal do Paraná 2009 (Tese de Doutorado).

RIBEIRO, L. C. de Q. (Org.). Hierarquização e identificação dos espaços urbanos. Rio de Janeiro: Letra Capital/Observatório das Metrópoles, 2009.

RIBEIRO, L. C. de Q; SILVA, É. T. da; RODRIGUES, J. M. Metrópoles brasileiras: diversificação, concentração e dispersão. Revista Paranaense de Desenvolvimento. Curitiba, n. 120, p. 177-207, 2011.

SANTOS, M. A natureza do espaço: espaço e tempo; razão e emoção. 4 ed. São Paulo: Edusp, 2009.

SCOTT, A. J.; AGNEW, J.; SOJA, E. W.; STORPER, M. Cidades-regiões globais. Espaço \& Debates, n. 41, 2001.

SOUZA, M. L. de. ABC do desenvolvimento urbano. Rio de Janeiro: Bertrand Brasil, 2003. 
TRINDADE JÚNIOR, S. C. da. A cidade dispersa: os novos espaços de assentamentos em Belém e a reestruturação metropolitana. São Paulo: FFLCH/USP, 1998 (Tese de Doutorado).

ULLMAN, E. L. Geography as spatial interaction. Seatle and London: University of Washington Press, 1980.

VILLAÇA, F. A delimitação territorial do processo urbano. São Paulo. 1997. Disponível em: http://www.flaviovillaca.arq.br/pdf/intra497.pdf. Acesso em 07 de fevereiro de 2016.

VILLAÇA, F. O espaço intra-urbano no Brasil. 2 ed. São Paulo: Nobel, FAPESP, Lincoln Institute, 2001.

Willame de Oliveira Ribeiro

Geógrafo, Professor Assistente IV da Universidade do Estado do Pará - UEPA e Doutorando em Geografia pela Universidade Estadual Paulista - UNESP/Campus Presidente Prudente.

Avenida Augusto Montenegro, 4100, Condomínio Chácaras Cedro, Apto. 1002 A, Parque Verde, Belém. CEP: 66635-110.

E-mail: willame.geo@gmail.com

Recebido para publicação em outubro de 2016 Aprovado para publicação em março de 2017 